\title{
Un cuento hispano en la Araucanía*
}

"Ese gran viajero proteiforme se reconoce bajo sus mil trajes"

(Roger Pinon, al referirse al cuento folklórico)

\section{EL NARRADOR Y SU CIRCUNSTANCIA}

Mientras los intelectuales de las grandes ciudades debaten los problemas de la modernidad y la postmodernidad y mientras en la Feria del Libro los escritores firman los ejemplares de sus obras como un modo de manifestar a sus lectores la voluntad de hacer prevalecer su individualidad creadora, en los rincones más ocultos del espacio rural hay otros hombres que, casi en los umbrales del tiempo próximo a otro siglo, conservan a través de la memoria y la oralidad antiguas composiciones creadas por alguien que se ha vuelto anónimo y recreadas y reelaboradas por participación colectiva de unos y otros hablantes. Los portadores de estos textos orales son normalmente personas con muy escasa instrucción escolar, pero de ágil memoria y gran destreza expresiva. Así, el hombre que narró este cuento se llama Artemio Caniuqueo Painén. Es mapuche y reside en la localidad de Pocuno (comuna de Nueva Imperial, en pleno corazón de la Araucanía). Tiene 45 años de edad y declara que lo aprendió, junto con otros relatos de su repertorio, cuando era un niño de unos 5 ó 6 años, de boca de su padre. Reconoce que ha mantenido en la memoria sólo parte de esa herencia narrativa y hoy trata de actualizarla para transmitirla a sus hijos. Su padre era bilingüe: hablaba mapudungun y castellano, pero a sus hijos les hablaba preferentemente en castellano. Por eso don Artemio se comunica casi únicamente en esta lengua. Declara que sabe muy poco de mapudungun. Sus hijos son todos monolingües de castellano. Su situación lingüistica es similar a la de muchos miembros de su grupo étnico. En medio de tanto conflicto vivido por los efectos de la colonización, en medio de

* Nota previa: El texto aquí analizado forma parte de los materiales verbales registrados en el marco del proyecto de investigación núm. 1950760, financiado por FONDECYT y llevado a cabo en la Universidad de La Frontera durante los años 1995-1996. El proyecto tiene como tema de estudio la "Situación interlingüística castellano-mapuche en la comuna de Nueva Imperial (IX Región). 
tantos encuentros y desencuentros producidos entre colonos y nativos, algunas amables semillas de la cultura popular hispánica han dejado aislados brotes entre esta "gente de la tierra".

Don Artemio cursó sólo los primeros años de la escuela básica y ha pasado la mayor parte de su vida en esta localidad rural, donde es propietario de una pequeña parcela que dedica a cultivos agrícolas; pero reconoce que también ha trabajado temporalmente como jornalero en fundos de la región, experiencia que le ha permitido compartir con otros campesinos algunos frutos del gran árbol de la narrativa folklórica.

\section{CUENTO hisPano-EUROPEO EN la ARAUCANía}

Es sorprendente el caso de este narrador, pues a pesar de ser mapuche no conoce relatos que revelen raíces indígenas; en cambio, demuestra suficientemente haber asimilado muy bien algunos cuentos tradicionales transmitidos por hispanohablantes. La narración aquí comentada es claro ejemplo de esta vertiente cultural, pues contiene, como se verá más adelante, los elementos estructurales del cuento maravilloso hispano-europeo.

Éste no es, sin embargo, un caso fortuito. Quienes han estudiado las narraciones araucanas han comprobado una gran capacidad receptiva de los mapuches en relación con los cuentos maravillosos de raíz hispánica. Seguramente exageró Rodolfo Lenz cuando afirmó que "los mapuches se han asimilado casi todo el tesoro de la literatura popular española " ${ }^{1}$. Pero esta hipótesis ha sido precisada por Yolando Pino a la luz de una información más amplia sobre la narrativa popular. Después de haber compulsado unas doscientas narraciones araucanas publicadas, $y$, exceptuando los textos exclusivamente míticos, las leyendas etiológicas e históricas y los relatos históricos y descriptivos, ha concluido que amás de la cuarta parte de ellas son cuentos de encanto de origen indoeuropeon y en las restantes ha encontrado insertos "variados motivos de cuentos universales" ${ }^{2}$.

\section{ASPECTOS ESTRUCTURALES}

Una versión es una de las varias manifestaciones del texto folklórico, producto verbal que ha vivido y vive oralmente a través de variantes. Si

1 Cit. por Yolando PINO SAAvedRA, "Las narraciones araucanas", Archivos del Folklore Chileno, núm. 9 (1971), pp. 9-23; p. cit. 17. Ver también su obra Cuentos mapuches de Chile (Santiago: Ediciones de la Universidad de Chile, 1987).

2 Y. PINO SAAVEDRA, op. cit., pp. 17-18. 
la estructura profunda del texto tiende a la permanencia, siempre los detalles de una versión oral dejan en evidencia inevitables variaciones. En este sentido, la versión es un producto verbal vinculado a un texto más complejo, pero en sí misma también tiene unidad de contenido y, por lo tanto, es legítimo examinar su articulación narrativa y su lógica interna.

A diferencia del esquema tradicional de cuento maravilloso en que la boda como objeto del deseo es la culminación de una serie de acciones que ponen a prueba la entereza del héroe ${ }^{3}$, en esta versión la boda es el suceso inicial que motiva una serie de acciones posteriores destinadas a anular dicho logro. En efecto, un hombre rico llamado "Cuerpo sin Alma" toma como esposa a una de tres hermanas. Hasta aquí todo transcurre con normalidad. Pero el conflicto se desencadena a partir del momento en que, de manera engañosa, el hombre rico consigue seducir a las otras dos hermanas para que convivan también con él. "Cuerpo sin Alma" aparece entonces como agresor, como alguien que transgrede o quebranta las normas internas de un grupo familiar: los padres y los tres hermanos de las jóvenes se conduelen del daño infligido y son precisamente los tres hermanos (Juan, Pedro y Manuel) los que asumen luego el papel de oponentes al emprender la tarea de ir, en forma sucesiva, al rescate de las hermanas cautivas. En tal intento se enfrentan con obstáculos difíciles de vencer. Los obstáculos son también tres, nueva evidencia de estructura ternaria tan frecuente en la estética del cuento folklórico, resto seguramente de la antigua magia del número tres: un "toro bravo", un "potro mañoso y bravo" y un "carnero bravo". Juan sucumbe ante el primer obstáculo; Pedro vence el primer obstáculo, pero sucumbe ante el segundo; y sólo Manuel, el tercero de los hermanos, vence los tres obstáculos y de este modo logra erigirse en el verdadero héroe del relato. Forma parte también de la estructura actancial un adyuvante ${ }^{4}$ o ayudante del héroe:

3 Ver E. M. MELETINZKY, "Problème de la morphologie historique du conte populaire", Semiótica II, núm. 2 (1970), pp. 128-134. Opina este autor que en el cuento maravilloso "Le mariage fabuleux est le dernier échelon de la chaîne syntagmatique du sujet, l'élément le plus important de la sémantique et le plus haut degré de la hiérarchie axiologique", p. 131. Recordemos también que en el marco de las funciones del cuento maravilloso señaladas por Propp, la última de la serie, es decir la núm. XXXI, corresponde precisamente a matrimonio. Ver Vladimir PROPP, Morfología del cuento, trad. española de Lourdes Ortiz (Madrid: Fundamentos, 5. ${ }^{a}$ ed., 1981), pp. 37-74. Cfr. Eduardo BARRAZA, “La boda como objeto del deseo en cuentos orales de Osorno", Revista de Folklore, núm. 149 (1993), pp. 151-155. Dice este estudioso: “En los relatos seleccionados para esta descripción, la boda constituye el objetivo que el héroe se propone para sín, p. 152.

4 Este término fue introducido por Guy Michaud (en sus Techniques de l'oeuvre), según A. J. GREIMAS, quien lo emplea frecuentemente en su Semántica estructural (Madrid: Gredos, 2. ${ }^{a}$ reimpresión, 1976). 
una de las jóvenes cautivas es quien revela a su hermano Manuel dónde se encuentra el objeto oculto que mantiene la vida de "Cuerpo sin Alma". Sin esta colaboración fundamental, sería muy difícil que el héroe pudiera descubrir el secreto. Después enfrenta al agresor, y en tal empresa los propios medios siempre resultan limitados. Para que ella resulte exitosa debe intervenir una fuerza superior alojada en algún objeto mágico. En esta versión intervienen varios elementos auxiliares, algunos de la vida cotidiana y sólo uno del ámbito mágico, aunque no se trata propiamente de un objeto, sino de un poder superior. En todo caso, estos distintos elementos auxiliares son traspasados al héroe por donantes: a) un mosquito le da fortaleza física a través de un elemento natural, como es el "agua", y la facultad sobrenatural de poder metamorfosearse en un insecto (concretamente en otro "mosquito") o en un ave de rapiña ("peuco"); b) un cuidador de ganado, en reconocimiento a su buen servicio en la hacien$\mathrm{da}$, le regala tres objetos propios del trabajo campestre: uun lindo caballo", "un buen lazo" y "una daga grande". Con la ayuda de estos objetos del mundo cotidiano y sobre todo con la de las virtudes o poderes mágicos conferidos por el mosquito, el héroe logra aprehender el objeto que hasta ese momento hacía invulnerable al agresor: el huevo donde tenía depositada su alma, misteriosa fuerza vital. El huevo es fuente de vida, pero también es su negación, puesto que al romperse en la frente del agresor inevitablemente le provoca la muerte.

Manuel, al dar muerte al agresor, rescata a sus hermanas, las reintegra al grupo familiar y de este modo restablece el orden que había sido quebrantado por una fuerza externa.

Los principales motivos estructurantes de las acciones son también tres: 1) la "muchacha seducida con engaño por un hombre rico", que parece ser transformación del motivo tradicional de la "princesa (o doncella) raptada por un monstruo (u ogro)" (R 11.1); 2) la "señal de la vida" (E 761); y 3) "la vida separada del cuerpo y oculta en un huevo", combinación de los motivos E 710 ("el alma externada") y E 711.1 ("el alma en un huevon). El primer motivo se inscribe en la esfera de acción del agresor y se desarrolla en tres momentos, puesto que son tres hermanas las requeridas en forma sucesiva (para esposa y convivientes) por "Cuerpo sin Alma". El segundo motivo se inscribe en la esfera de acción de los pseudohéroes y del héroe en su trayectoria hacia el rescate. El primer hermano que se aleja del hogar para intentar el rescate, antes de partir en pos de su objetivo, advierte a sus familiares que si no regresa en un número determinado de días es porque habrá muerto. El segundo hermano hace igual advertencia. El tercero, en cambio, deja como seña una flor, pero no una flor cualquiera, sino una flor ligada mágicamente a su existencia: si se 
marchita indicará que él ha muerto; si se mantiene, será señal de que sigue vivo.

Es interesante también observar la estructura ternaria que tiene el tercer motivo mencionado, el cual aparece ligado a la esfera de acción del agresor y luego a la del héroe. En la versión que aquí se analiza se manifiesta como la vida (del malhechor) separada del cuerpo y oculta en un huevo. Para tener acceso a ese lugar secreto, el héroe debe dar muerte a un toro que guarda en su interior un león; luego también debe dar muerte al león en cuyo interior se aloja una paloma; el paso final es desgarrar la paloma para coger el huevo que oculta la vida del malhechor. "Toro" $\rightarrow$ "león" $\rightarrow$ "paloma" forman una tríada que va de mayor a menor y de continente a contenido, del animal más corpulento, fuerte y agresivo al más pequeño, débil y pacífico que contiene el secreto; aunque este ser más pequeño, frágil y pacífico es también más esquivo, porque puede volar. El héroe sólo logra darle alcance transformándose a la vez en ave, pero no en un ave similar, sino en otra distinta, fuerte y agresiva, como es el "peuco", un ave falcónida, un ave de presa. Así la "paloma" contrasta con el peuco en cualidades y funciones. La victoria del peuco frente a la paloma es el preludio del fin: la victoria del héroe frente a su agresor.

\section{FILIACIÓN}

Es ésta una versión de un cuento folklórico que ha tenido algún grado de difusión en nuestro país, ya que otras versiones constan, por ejemplo, en las compilaciones de Laval ${ }^{5}$, Pino Saavedra ${ }^{6}$ y Foresti Serrano ${ }^{7}$ y está publicada también una versión recogida por nosotros en Osorno ${ }^{8}$. Rodríguez Almodóvar incluye tal cuento entre los más populares relatos maravillosos del ámbito hispánico, lo tipifica y lo presenta con el nombre de Los animales agradecidos ${ }^{9}$. En el catálogo internacional de Aarne-

5 Ramón LAVAL, Cuentos populares de Chile. Selección y estudio de Alfonso M. Escudero, O.S.A., (Santiago de Chile: Nascimento, 1968), pp. 168-173.

6 Yolando PINo SAavedra, Cuentos folklóricos de Cbile (Santiago de Chile: Edit. Universitaria, 1960), t. I, pp. 49-67.

7 Carlos FORESTI SERRANO, Cuentos de la tradición oral chilena. 1. Veinte cuentos de magia (Madrid: Ínsula, 1982), pp. 41-45.

8 C. Contreras, E. Barraza, P. Álvarez-Santullano y L. Rodríguez, Cuentos orales de raíz hispánica. Anejo núm. 14 de Estudios Filológicos (Valdivia: Universidad Austral de Chile, 1992), pp. 69-81.

9 Antonio Rodríguez Almodóvar, Los cuentos maravillosos españoles (Madrid: Crítica, 1982), pp. 126- 130 . 
Thompson corresponde al Tipo $302-$ El corazón del ogro (o diablo) en el buevo-, cuento de magia con adversario sobrenatural ${ }^{10}$. Asimismo en el más reciente Catálogo tipológico del cuento folklórico español, de Camarena y Chevalier, el Tipo 302 aparece consignado con el título de La vida externada y como ejemplo del repertorio español se reproduce una versión publicada por A. M. Espinosa en 1946 con el título de La princesa encantada ${ }^{11}$. Más allá del área hispánica, según la autorizada opinión de Thompson, este cuento ha sido muy popular desde Irlanda hasta la India. En la versión arquetípica, el héroe, premunido de un auxiliar mágico, va a rescatar a una princesa que ha sido raptada por un monstruo. "La encuentra, y juntos urden un complot en contra de la vida de su desagradable galán. Ella engaña al monstruo para que le diga dónde guarda su corazón o con qué está atada su vida. Le dice que su corazón se encuentra en cierto huevo de difícil acceso, o en el de un pájaro o en el de un insecto guardados por una peligrosa bestia. El héroe sigue las instrucciones que le da ella y encuentra el corazón del monstruo. Cuando destruye el corazón, el monstruo muere y el héroe conduce a la princesa a su casa, recibe su recompensa y toma a la princesa como esposa" ${ }^{12}$.

La versión recogida en la Araucanía difiere de la versión arquetípica en algunos aspectos superficiales. Así, por ejemplo, en el Cuento Tipo el agresor es un monstruo y la cautiva una princesa, y en la versión local el agresor es un hombre rico y las cautivas son tres hermanas; el Cuento Tipo insiste en el corazón como centro vital oculto en un huevo; en la versión local no hay una referencia explícita al corazón, aunque sí a la vida (o al alma) alojada en un huevo; en el Cuento Tipo las acciones culminan en la boda; en la versión local, culminan con la reintegración de las cautivas en el grupo familiar. Obviamente, estos detalles que varían son externos o de superficie; pero se puede decir que en el nivel profundo de la narración, o sea, en el de su articulación semántica, hay plena coincidencia. Así en un nivel abstracto es posible llegar a precisar la siguiente formulación globalizante de su contenido: Un malhechor seduce o rapta a una joven (o a más de una) y la mantiene en cautiverio. El rescatador, después de sortear varios obstáculos, ayudado de poderes mágicos logra dar muerte al malhechor, aparentemente invulnerable, rescata el objeto del rapto (o del daño infligido) y restablece el orden perturbado.

10 Stith Thompson, El cuento folklórico, trad. de Angelina Lemmo (Caracas: Univ. Central de Venezuela, 1972), pp. 63-64.

11 Julio CAmarena LaUCirica y Maxime CHEvalier, Catálogo tipológico del cuento folklórico español. Cuentos maravillosos (Madrid: Gredos, 1995), pp. 34-37.

12 S. Thompson, op. cit., pp. 63-64. 
El desarrollo de esta fórmula se ajusta bastante bien a las fases del ciclo definido por Brémond en torno al curso que siguen las acciones en el cuento folklórico: el ciclo puede empezar con un estado de carencia o con un estado satisfactorio ${ }^{13}$. En la versión que se está analizando las fases siguen la siguiente secuencia:

estado satisfactorio $\rightarrow$ proceso de degradación $\rightarrow$ estado de carencia

$\rightarrow$ proceso de restauración $\rightarrow$ restablecimiento del estado satisfactorio

\section{MÁS ALLÁ DEL MUNDO COTIDIANO: LOS PODERES MÁGICOS}

El cuento maravilloso suele contener algunos elementos de la circunstancia inmediata del narrador, pero esos aspectos de la vida cotidiana sólo sirven como nexos con un mundo distante, un mundo donde el tiempo y el espacio pierden sus contornos y los personajes pueden pasar de una esfera natural a otra sobrenatural con especiales poderes mágicos. Así, en la versión que estamos analizando, de pronto las acciones parecen transcurrir en un espacio que contiene elementos de la estructura agraria regional: un hombre que posee hacienda y tres fundos hace prevalecer su poder basado en la riqueza. Sin embargo, el poder que tiene este hombre está por encima de toda circunstancia cotidiana y de toda riqueza material. El poder que tiene "Cuerpo sin Alma" es sobrenatural: la facultad de poder separar su vida y esconderla en un lugar secreto para que su cuerpo sea invulnerable.

Y este hecho mágico sólo será contrarrestado con otro poder mágico. Ese otro poder mágico es el que acompaña al héroe. En la versión que aquí se analiza el héroe se llama Manuel, tiene un nombre familiar, y sus acciones iniciales parecen bastante similares a las que cualquier joven realiza en la vida real; sin embargo, las acciones posteriores revelan que tiene un poder superior, que lo distingue, por ejemplo, de sus hermanos. En verdad, su condición heroica se intuye desde el momento en que el primero de los hermanos decide emprender la búsqueda, porque es un tópico repetido hasta la saciedad en el cuento tradicional que el último de tres hermanos es el que siempre triunfa. Su vínculo con poderes superiores se confirma muy pronto. Manuel es el único de los tres hermanos que, en el momento de partir hacia la ejecución de su empresa, advierte su suerte futura a través de un hecho mágico: si la flor que deja

13 Claude BRÉmOND, "Morphology of the French Folktale", Semiótica II, 3 (1970), pp. 247-276. 
plantada en la casa se seca, su búsqueda habrá fracasado y le habrá sobrevenido la muerte; si la flor mantiene su frescura, es señal de que sigue vivo. Más adelante, es el único que vence todos los obstáculos y es el único que adquiere de un donante el poder mágico para transformarse en otro ser de naturaleza diferente, ya sea un mosquito o un ave de presa, con el propósito de poder lograr con menor dificultad su objetivo final.

\section{El ECO DE OtRAS VOCES, DE OTROS TIEMPOS}

El cuento folklórico está lejos de ser un fenómeno local, regional o nacional. Cuanto más se estudia, más se verifica su carácter internacional. $\mathrm{Y}$ en muchos casos en que se ha tratado de precisar la antigüedad de un cuento, o de un motivo como unidad narrativa menor y típicamente estructurada, resulta sorprendente su vitalidad a través del tiempo, vitalidad sostenida por la memoria y los actos de habla y en algunos casos también por el apoyo de versiones escritas e incluso por su ocasional tratamiento literario ${ }^{14}$.

Un cuento folklórico como el que aquí se está analizando, que pertenece a la categoría de cuentos maravillosos, nos sumerge en un mundo que parece de pura fantasía; sin embargo, es posible que en otros tiempos no todo haya tenido ese carácter. Vladimir Propp, al estudiar las raíces históricas del cuento, sostiene que por lo general el cuento maravilloso tuvo en otros tiempos vínculos estrechos con creencias y prácticas rituales muy arraigadas en determinadas sociedades. "El relato maravilloso - dice- ha conservado las huellas de numerosísimos ritos y costumbres: sólo si se les confronta con los ritos es posible explicar genéticamente muchos motivos" ${ }^{15}$. Ahora bien, lo que más llama la atención en el desarrollo de las acciones del relato comentado es el motivo de "la vida separada del cuerpo y oculta en un huevo" o, si se quiere, de acuerdo con el índice de Aarne y Thompson, en plural, los motivos de "el alma externada" y "el alma en un huevo". Al respecto George Frazer proporciona abundantes testimonios de pueblos que él denomina "salvajes" o "primitivos" de distintas partes del mundo que efectivamente han creído que el alma puede desprenderse del cuerpo y que durante esa separación es necesario tomar las precauciones para que esa

14 Véase, por ejemplo, María Rosa LIDA, «El cuento hispanoamericano y la literatura, en El cuento popular y otros ensayos (Buenos Aires: Losada, 1976), pp. 1-80.

15 Vladimir Propp, Las raíces históricas del cuento, trad. de la versión italiana por José Martín Arancibia (Madrid: Fundamentos, 3. ${ }^{a}$ ed., 1981), p. 24. 
contraparte, que es fuente de vida, no sea dañada por enemigos: protegiendo el alma se protege también el cuerpo. "Concebida así — dice Frazer- no es necesario en absoluto que la vida esté en el hombre; puede hallarse ausente de su cuerpo y continuar aún animándolo en virtud de una especie de simpatía o acción telepática. En tanto que este objeto, que él llama su vida o su alma, permanece incólume, el hombre estará bien; si ella está dañada, él sufrirá, y si ella es destruida, él morirá" ${ }^{16}$.

El mismo Frazer comenta una gran variedad de relatos populares que - según él- "son un fidedigno reflejo del mundo tal como apareció ante la mente primitiva" ${ }^{17}$. Actualmente no se puede tomar muy en serio la tesis del "fidedigno reflejo", porque si esa afirmación pudiera tener relativa validez para el relato mítico, no la puede tener para el cuento maravilloso, puesto que -como dice Propp- "El relato maravilloso no es una crónica ${ }^{18}$. Y no lo es en la medida en que sólo a veces puede contener una correspondencia directa con una creencia o con un rito; en otras ocasiones puede presentar una "transposición del sentido". Por transposición del sentido entiende Propp "la sustitución en el relato maravilloso de un elemento cualquiera o de algunos elementos del rito, que se han vuelto superfluos o incomprensibles como consecuencia de cambios históricos, por otro elemento más comprensible, ${ }^{19}$.

En todo caso, el relato maravilloso cuanto más se ha desligado de un determinado sistema de creencias, mayor autonomía ha adquirido como creación verbal. Sin embargo, es posible que uno de los factores que hayan contribuido a su difusión en el espacio geográfico y en el tiempo sea la persistencia de otros sistemas de creencias en los grupos sociales o en determinadas personas que han mantenido en la memoria tales relatos. $Y$ aunque no fuera así, siempre lo mágico ejerce un atractivo especial, porque en esa esfera se subliman las limitaciones humanas: la flaqueza puede transformarse en fortaleza, y lo poderoso, cuando se asienta sobre bases engañosas, se desmorona; las carencias se transforman en logros y los logros, cuando se fundan en el daño, tienen una vida efímera. En el mundo del cuento maravilloso todo o casi todo es posible. El hombre (como Manuel, el héroe del cuento "Cuerpo sin Alma") puede transformarse en un ser tan diminuto como un mosquito para observar y escuchar sin ser visto; o puede transformarse en pájaro para alcanzar lo inalcanzable. Las

16 Sir James George FRAzER, La rama dorada. Magia y religión, versión española de Elizabeth y Tadeo I. Campuzano (México-Buenos Aires, 5. ${ }^{a}$ ed., 1965), p. 750.

17 G. Frazer, op. cit., p. 750.

18 V. Propp, op. cit., p. 25.

19 V. PROPP, op. cit., p. 25. 
acciones transcurren en un pasado remoto, pero inespecífico, y en un espacio sin nombre y sin orillas.

A estas alturas es imposible saber en qué lugar o país preciso y en qué tiempo se originó el cuento de "Cuerpo sin Alma". Hablamos de filiación hispano-europea únicamente porque es indudable que en nuestro país ingresó y se difundió a través de los colonos españoles. Pero siempre quedará la duda: no se sabrá si se originó en Occidente o tal vez en Oriente. Como ya se ha dicho, Thompson asegura que el cuento El corazón del ogro (o diablo) en el huevo es muy popular desde Irlanda hasta la India. También Frazer señala esta área de difusión correspondiente a los pueblos arios y proporciona numerosos ejemplos de relatos de tradición oral y de creencias y prácticas rituales relacionadas con el alma externada (oculta en algún objeto, animal o planta). Y, luego, agrega que dicha tradición se encuentra también en pueblos de otras raíces ${ }^{20}$. Mircea Eliade es otro estudioso que alude a tradiciones antiguas y modernas que corresponden a sistemas de creencias seguramente previas al desarrollo del cristianismo o a la supervivencia de cierto paganismo refugiado especialmente entre campesinos europeos ${ }^{21}$. Pero, por otra parte, es sintomático que un episodio similar aparezca nada menos que en la tradición medieval arábiga, fijada en ese monumento narrativo que es Las mil y una noches, obra muy difundida en los países occidentales ${ }^{22}$. Cuando se narra la historia del príncipe, y luego joven monarca, Seifu-l-Muluk (noches 422 a 437), aparece un relato menor, enmarcado, en el que se cuenta cómo este joven libera a Daula Jatún, hermana de su pretendida, que permanecía cautiva por Hatem, maldito hijo de Al-Asrak, "rey de los genios" (noche 430). La muchacha consigue con argucias que su raptor le confiese dónde tiene oculta su alma, raíz de su invulnerabilidad.

Daula Jatún, a la vez, confía el secreto a Seifu-l-Muluk:

Has de saber - dijome entonces él- que, al nacer yo, predijeron los astrólogos que mi alma moriría a manos de un hijo de los hijos de los reyes de casta humana. Por lo que, al saberlo, cogí mi alma y la metí en el buche de un pájaro y guardé al pájaro en un estuche y el estuche en otros siete estuches y siete cajitas y lo metí todo en un arcón de alabastro y enterré el arcón de alabastro en el fondo del océano que ciñe la tierra, porque esas regiones caen muy lejos del mundo de los hombres y ninguno de ellos tiene hasta allí acceso ${ }^{23}$.

20 FrAZER, op. cit., p. 756.

${ }^{21}$ Mircea ElAADE, Mito y realidad (Barcelona: Labor, 6. ${ }^{a}$ ed. en español, 1985), pp. $170-211$

22 ANÓNimo, El libro de las mil y una noches, trad. de R. Cansinos Assens, 3 vols. (Madrid-México-B. Aires: Aguilar, 1966).

23 Id., vol. II, pp. 591-592. 
Como un hecho de magia sólo puede anularse con otro elemento mágico, Seifu-l-Muluk estaba en una situación privilegiada para poder aniquilar al agresor, ya que llevaba en su dedo el virtuoso anillo de Soleimán. Éste es el auxiliar mágico que le posibilita el triunfo.

La muerte del agresor era previsible:

Y Seifu-l-Muluk al oír aquello, obedeció a Daula Jatún y le retorció al pájaro el pescuezo y lo mató.

Y en el acto desplomóse el genio en tierra, convertido en un montón de pavesas ${ }^{24}$.

También en este caso el héroe restablecerá el orden perturbado.

Se puede observar que hay cierta semejanza entre este relato y el cuento de "Cuerpo sin Alma". Obviamente, en un nivel superficial se presentan también notables diferencias. Pero en un nivel abstracto la correspondencia es muy estrecha, lo que hace suponer que ambos relatos derivan de una común matriz generativa, cuya fórmula puede ser la ya enunciada y que conviene repetir: Un malhechor seduce o rapta a una joven (o a más de una) y la mantiene en cautiverio. El rescatador, después de sortear varios obstáculos, revestido de poderes mágicos logra dar muerte al malhechor, aparentemente invulnerable, rescata el objeto del rapto (o del daño infligido) y restablece el orden perturbado.

En rigor, hay unas normas sociales subyacentes, unas normas que afectan el plano de la moral familiar. Van Dijk señala que en el esquema narrativo o superestructura del cuento, del cuento tradicional se entiende, la última fase corresponde a la categoría llamada "moraleja" ${ }^{25}$. En efecto, lo que rechaza o condena la regla moral implícita en este cuento es la seducción engañosa de la mujer o el rapto y, por supuesto, el cautiverio, la privación irrestricta de la libertad personal.

En conclusión, don Artemio Caniuqueo Painén, hombre nativo de la Araucanía, al entregar su versión del cuento "Cuerpo sin Alma" ha recreado, sin pretenderlo, una de las variadas formas de un complejo narrativo que seguramente ha recorrido distintos espacios y tiempos con figuraciones siempre cambiantes. Más allá de la voluntad del narrador, es el estudioso de la narración quien siente la necesidad de establecer alguna relación intertextual, porque ésta, aunque sea mínima, sirve para encontrar un mayor sentido al producto verbal. Por otra parte, el proceso de abstracción posibilita el descubrimiento de los elementos unitarios subyacentes. Es aquí donde también cobra sentido el epígrafe de Roger Pinon, ele-

$24 \quad$ Ibid., p. 592.

25 Teun VAN DIJK, Estructuras y funciones del discurso (México: Siglo XXI, 5. a ed. en español, 1988), p. 53. 
gido para este trabajo: "Ese gran viajero proteiforme se reconoce bajo sus mil trajes".

\section{APÉNDICE}

\section{CUERPO SIN ALMA}

$\begin{array}{ll}\text { Narrador } & \text { : Artemio Caniuqueo Painén } \\ \text { Edad } & : 45 \text { años } \\ \text { Escolaridad } & \text { : básica incompleta } \\ \text { Actividad } & : \text { agricultura } \\ \text { Localidad } & : \text { Pocuno (comuna de Nueva Imperial) } \\ \text { Antecedente } & : \text { Aprendió este cuento a la edad de } \\ & 6 \text { ó } 7 \text { años, de boca de su padre. }\end{array}$

Fecha del registro: 30 de noviembre de 1996.

Se trata de una persona que se llamaba Cuerpo sin Alma. Resulta de que ${ }^{26}$ ese hombre era un... un comerciante ¿no? Tenía mucha plata ${ }^{27}$, muchos biene(s) ${ }^{28}$. Y se enamoró de una niña de un matrimonio que tenía seis hijos: tres hijas y tres hijos varone(s). Entonce(s) se enamoró de una y la pidió y se casó con ella y se la llevó $\mathrm{pu}(\mathrm{es})^{29}$. Estuvo conviviendo con ella.

Y después que ya estuvo un tiempo... y de repente vino (d)onde los suegro(s) y le(s) dijo:

-Suegro(s), mi esposa se encuentra muy sola y quiere que... que vaiga ${ }^{30}$ una de las hermana(s) a acompañarla.

26 No es el único caso de dequeísmo que aparece en el texto. Por ejemplo, más adelante se lee: "Caminó tanto el hombre de que se le terminó el cocaví.

27 plata: 'dinero'. Cfr. ACADEMIA CHILENA, Diccionario del habla chilena (Santiago de Chile: Edit. Universitaria, 1978), p. 181. En adelante DHCH.

28 Fonéticamente, es regular la aspiración de $s$ en situación implosiva. La aspiración deviene en caída de dicha consonante en el adverbio entonces ( $>$ entonce). También es imperceptible en el clítico de función complementaria indirecta les $(>l e)$. En tal caso sólo el contexto indica que se trata de una forma de plural. Asimismo, tiende a perderse en el plural de la última palabra de una secuencia de formas pluralizadas. En general, el debilitamiento o pérdida de $s$ implosiva, sobre todo al final de palabra, se señala entre paréntesis. También se utilizan paréntesis para indicar el debilitamiento o pérdida de la consonante $d$, particularmente en situación intervocálica y al final de palabra.

29 La forma pues, reducida a $p u$, suele perder su función conjuntiva o la de elemento continuativo para asumir una función de mero apoyo fonético o tal vez de refuerzo expresivo.

30 vaiga: variante arcaica de la forma subjuntiva vaya, como la conservada en leonés y aragonés. Cfr. Alonso ZAMORA VICENTE, Dialectología Española (Madrid: Gredos, 2. ${ }^{a}$ ed., 3. ${ }^{2}$ reimpresión, 1979), pp. 196 y 262. 
Pero era con engaño. Entonce(s) y así los viejito(s) le dieron permiso a la hija. Y se llevó ${ }^{31}$ la otra hermana. Así que también la tomó por esposa pu(es).

Y después ya, al más tiempo ya, no quedó conforme con eso y trató de convencer a la otra pu(es), pedir la otra hija. Y así al final se llevó las tres hija(s).

Y cuando ya se llevó las tres hija(s), entonce(s) de ahí los hermano(s) extrañaron: que por qué no venían las hermana(s) a ver a los padre(s). Entonce(s) los viejito(s) se entristecieron. Lloraban por sus hija(s), porque cómo podían olvidarse de ellos pu(es) las tres hija(s). Y que no sabían nada ni del yerno, porque se perdió pu(es), no vino nunca más.

Entonce(s) uno de los hermano(s) - uno se llamaba Juan, el otro se llamaba Pedro, el último se llamaba Manuel- ... entonce(s) el Juan fue el primero que puso de intención de ${ }^{32}$ ir a ver a sus hermana(s). Entonce(s) dijo:

- Yo voy a ir y voy a tener que llegar donde vive este hombre.

Entonce(s) se preparó con cocaví ${ }^{33}$, porque vivía lejos. Y como en esos año(s) no había locomoción, se caminaba de a pie ${ }^{34}$, a caballo. Quizás cuánto sería la distancia. Y salió y le(s) dejó dicho a los padre(s) que si no llegaba en tantos día(s), que... que contaran que estaba muerto, porque no iba a volver. Entonce(s) cuando salió de camino, dicen que de repente caminando llegó a un fundo ${ }^{35}$. Y to(d)os esos fundo(s) eran... eran del hombre ese ${ }^{36}$ pu(es), del Cuerpo sin Alma, le llamaban el Cuerpo sin Alma. Entonce(s) había que pasar primeramente por un fundo donde había un piño de... una hacienda de animales vacuno(s). Y ahi ${ }^{37}$ había un toro. $\mathrm{Y}$ entonce(s)... y ese toro era bravo. Había que peliar ${ }^{38}$ con ese toro para poder pasar ahi. Entonce(s) los cuidadore(s) le dijeron a él:

-Aquí no pasa nadie: que el que dentra ${ }^{39}$ aquí tiene que morir.

31 En casos previsibles de uso de preposición $a$ en complemento directo relativo a persona, el texto refleja vacilación, es decir, presencia o ausencia de tal forma.

32 puso de intención de: 'manifestó la intención de'.

33 cocaví voz procedente del quechua y equivalente a 'víveres o provisiones para el viaje' cfr. Marius SALA et al., El léxico indígena del español americano (MéxicoBucaresti: Academia Mexicana y Editura Academiei Române, 1977), p. 40.

34 caminaba a pie: aunque parece expresión redundante, para el narrador el caminar involucra no sólo 'recorrer a pie cierta distancia', sino también 'avanzar por otros medios, por ejemplo, a caballo'.

35 fundo: 'finca, propiedad rural', voz plenamente vigente en Chile, aun cuando ZAMORA Vicente la considera uno de los arcaísmos de nuestro español de América (op. cit., pp. 425 y 429).

36 Es frecuente en el texto la posposición del adjetivo demostrativo al sustantivo: de ese hombre > del hombre ese.

37 El adverbio de lugar abi se ve afectado frecuentemente por la tendencia antihiática y, en consecuencia, se transforma en monosílabo: $a b i>a b i$.

38 La tendencia antihiática transforma fácilmente la voz pelear (trisílaba) en peliar (bisilaba), peleó en pelió, etc.

39 Conservación del antiguo verbo dentrar (entrar) "Con gran persistencia en la lengua popular", según Rodolfo OROz, La lengua castellana en Chile (Santiago de Chile: Edit. Universitaria, 1966), p. 343. 
Entonce(s) él dijo:

-No, yo voy a pasar.

Entonce(s) ahí, apenas dentró ya por el fundo, entonces el toro luego lo vio y se vino encima de él. Pelió con el toro y lo mató pu(es). Murió.

Y cuando ya no volvió el hijo, entonces los viejito(s) acá ya se pusieron a llorar, porque vieron que el hijo estaba muerto. Que ése era su relato que le dejó dicho: que "En tanto(s) días si no llego, cuenten que estoy muerto".

$\mathrm{Y}$ ahí entonce(s) el otro hermano, el Pedro ${ }^{40}$, dijo:

-Yo voy a ir. Yo tengo que llegar. Algo le pasó a mi hermano. Y entonce(s) voy a... voy a buscal.lo ${ }^{41}$.

Y cuando salió, también dejó, igual que el otro, la misma seña: En tantos días si no llegaba, ya lo contaran por muerto, porque ya no llegaba. Así que ése también llegó a ese primer potrero. $\mathrm{Y}$ ahi el cuidador le dijo, igual que el otro.

Él dijo:

-No, si yo voy a pasar.

Así que ése era más diablo. Así que ése pelió con el toro y mató al toro pu(es). Y cuando ya mató al toro, siguió caminando. Después llegó a un potrero donde había hartos caballos. $\mathrm{Y}$ había un potro mañoso y bravo. $\mathrm{Y}$ asimismo le dijo el cuidador, porque cada... cada cuidador... o sea en cada fundo había cuidadore(s) ¿no?: que ahi no dentraba nadie. Entonce(s) ahi había que hablar con el que cuidaba ahi. Entonce(s) el que cuidaba le dijo:

- ¿Y cómo pasó para acá? - le dijo él-, siendo que aquí no pasa nadie.

$Y$ ahi le dijo:

-No, es que yo pasé.

-Aquí - le dijo-, uste(d) va a tener que peliar con el... con el potro más bravo que hay aquí. Si dentra para allá, aquí nadie pasa; aquí mueren los que llegan aquí.

Él le dijo:

-No, si yo voy a pasar.

Entonce(s) luego, cuando dentró al campo, y luego lo vio el animal bravo ese y se le vino ahí a patadas. Y ahi no pudo pu(es). Así que ahi el animal lo mató a él. Y murió. Ya no llegó pu(es). Llegaron los días indicado(s). Ya no llegó. Ya le(s) quedaba un solo hijo a los viejito(s) pu(es), que era el Manuel.

Entonce(s), cuando ya no llegó el otro hijo, entonce(s) ahí se apenaron ellos. Entonce(s) el otro hermano, el Manuel, dijo.

-Yo voy a ir. Yo voy a tener que llegar. Posiblemente mis hermano(s) han muerto, pero yo no voy a morir.

Entonce(s) él dejó una seña. Entonce(s) dijo:

-Voy a plantar una flor. Esta florcita van a tener que regal.lo ${ }^{42}$ todos los día(s). Cuando esta flor se seque, es seña que estoy muerto; y si no se seca - le(s) dijo-, es porque estoy vivo.

Así que esa seña le(s) dejó a los padre(s). Y salió. Así que cuando ya salió de camino, iba el mismo rumbo de los otros hermano(s). Y llegó al primer campo ese y

40 Es rasgo del estilo familiar el empleo del nombre personal acompañado de artículo.

41 Es común la lateralización de $r$ cuando va seguida de lateral.

42 El clítico lo puede asumir a veces la función de la. En el habla de este narrador es un hecho evidentemente esporádico. 
ahi ya no había peligro, porque el toro bravo había muerto pu(es). Así que ahí pasó bien. Después llegó al otro campo donde murió el otro hermano y ahí encontró a su hermano muerto también. Eran dos hermanos muerto(s) que tenía ya pu(es) en cada fundo. Entonce(s) ahí le dijo el mismo cuidador, le dijo:

-Mire - le dijo-, aquí tal día llegó uno y murió y aquí no... no pasa nadie.

Entonce(s) le dijo:

-No, yo voy a pasar.

Le abrió la puerta. Así que dentró al campo y luego se le vino el animal bravo ese a... a pegal.le, a patial.lo. Como son los caballo(s): patean. Y él... y se puso a peliar con el caballo pu(es), hasta que lo... lo cansó y lo mató; no fue capaz el caballo. Entonce(s) mató el caballo y ahi siguió, pasó, siguió caminando. A tanto ${ }^{43}$ caminar, despué(s) ya llegó a otro fundo más. Ése era el último fundo que tenía que pasar. Y ahí había un carnero bravo. Ahí había un... era crianza de gana(d)o que tenía el rico: miles de cabeza(s) de gana(d)o. Había un carnero bravo. Y ahí le preguntó el que cuidaba, le dijo:

— ¿Y cómo uste(d) pudo llegar aquí, siendo que aquí no llega nadie?

Ahí le dijo:

-No - le dijo-, yo pude pasar, sin problema.

Entonce(s) ahí le dijo:

- Mire, aquí yo le doy permiso - le dijo-, pero uste(d) sepa que si dentra aquí va a morir, porque este carnero es bravo.

Y ahi Manuel ya no le tuvo miedo, porque había pasado lo más bravo, lo más grande. El carnero era más chico pu(es). Y fue más fácil pa(ra) matal.lo.

Entonce(s) le dijo:

-No, deme permiso no más. Yo voy a dentrar. Porque voy en busca de mis hermana(s), quiero llegar allá.

$\mathrm{Y}$ ahí ése le preguntó pu(es):

— ¿Quedará muy lejos pa(ra) llegar a tal parte? -le dijo-. Tengo un cuña(d)o. Se llama Cuerpo sin Alma.

Y ahí le dijo él:

- No muy lejos - le dijo-, pero tiene que caminar bastante todavía.

Y entonce(s) ahi ya le dio la entrada. Y cuando dentró y luego lo vio el carnero que... que iba por la loma. Y se le vino el carnero a... a cornial.lo. Y luego él lo tomó, lo agarró: era fácil. Como era chico el animal, ése lo mató luego. Y después que lo mató, siguió caminando. Caminó tanto el hombre de que se le terminó el cocaví que llevaba. No le quedaba agua nada. Llegó en un cerro y no halló por donde cortar ${ }^{44}$. De ahi ${ }^{45}$ dijo:

-Ya, aquí ya no doy más. Aquí me voy a echar a morir.

Entonce(s) se botó en el campo, ahi, porque ya no podía caminar más pu(es). Tenía sed, tenía hambre. Entonce(s) dijo: llegar.

-Aquí me voy a botar a morir no más, porque ya no llegué a(d)onde tenía que

43 a tanto: tiene el valor de modo adverbial equivalente a 'de tanto'.

44 cortar: 'tomar una dirección, echarse a andar'.

45 La expresión de abi o de abi (y aun di abi) pasa a tener valor adverbial temporal equivalente a 'desde ese momento'. 
Entonce(s) acá los viejito(s) to(d)os los día(s) miraban las flore(s) pu(es). Así que ese día en la mañana amaneció marchita la flor.

Entonce(s) se entristecieron los viejito(s). Dijeron:

- ¿Por qué esta flor se quiere secar? A lo mejor nuestro hijo también va a morir.

Y en eso estaban ahí, cuando el Manuelito (es)taba bota(d)o. Se botó boca abajo.

Y de repente sintió una voz que le hablaba, le decía:

- ¡Manueliiito! ¡Manueliiito!

Y de repente él escuchó y miró: no vio a nadie.

$\mathrm{Y}$ ahi se quedó otra vez. Y al poco rato le vuelve a hablar otra vez:

- ¡Manueliiito! -le decía- ¡Manueliiito!

Y de repente vio un mosquito que había cerca. Y ése era el mosquito que le estaba hablando. Entonce(s) ese mosquito le habló, le dijo:

-Uste(d) ya va cerca [de] donde va a llegar. Yo le voy a ayudar - le dijo.

Entonce(s), al hablal.le el mosquito, agarró fuerza pu(es). Entonce(s) le dijo:

-Levántese y mire pa(ra) tal parte - le dijo-, allí hay una laguna.

Entonce(s) luego vio la laguna y se dirigió a la laguna, porque dijo: — Tomando agua me voy a fortalecer.

Entonce(s) fue, llegó al agua y tomó agua. Y ahí entonce(s), cuando lo llevó al agua el mosquito ese, iba el mosquito con él, entonce(s) le dijo:

- Yo te voy a ayudar en todo - le dijo.

Y cuando tomó agua y después... luego lo dirigió (d)onde tenía la casa el cuña(d)o pu(es), a(d)onde estaban las hermana(s). Entonce(s) cuando llegaron allá y no estaba na(da) el cuña(d)o, porque no paraba; era negociante el hombre. Entonce(s) cuando llegó y lo vio la hermana, lo conoció, se asustó la hermana. Entonce(s) le dijo:

-Manuel - le dijo-, ¿por qué has venido aquí? Aquí, el que llega aquí no vuelve -le dijo-, porque aquí mi esposo es mañoso: no quiere que llegue nadie.

Y le dijo:

-No, no temas - le dijo-. Yo sé cómo me voy a defender.

Así que cuando ya notó él que venía, como ya tenía la virtu(d) que el mosquito le había da(d)o, así que notó que él venía, entonce(s) salió pa(ra) ajuera ${ }^{46}$. Le dijo:

- Ya, chao ${ }^{47}$ - le dijo-. Por ahi me voy a ganar ${ }^{48}$.

Así que el hombre cuando llegó, encontró raro, porque habían llega(d)o unas persona(s). Se dio cuenta que había llega(d)o alguien. Ahi le preguntó a la esposa, le dijo:

- ¿Quién llegó? ¿Quién vino?

Ahí ellas le dijeron:

-No, no ha venido nadie.

Entonce(s)... Y Manuelito se convirtió en un... en un mosquito. Y él escuchaba to(d)o en una rendija de la casa. Ahí estaba escuchando lo que conversaba el cuña(d)o. $\mathrm{Y}$ a pesar de que el hombre ese no dejaba un mosco parar dentro de la casa pu(es), nada. Entonce(s) ahí escuchó toda la conversa ${ }^{49}$ que hizo el hombre.

46 Expresión redundante, pero bastante común en el habla popular. Más adelante el mismo texto contiene la expresión "dentró pa(ra) a(d)entro". Por otra parte, la consonante $f$ delante del diptongo ue suele velarizarse: [fwe] $>$ [xwe].

47 chao: forma familiar de despedida, procedente de ciao, voz italiana de saludo y también de despedida.

48 ganar(se): 'situarse, ubicarse'.

49 conversa: variante acortada de 'conversación'. 
Ya luego salió otra vez pu(es). Y ya más tarde llegó otra vez, nuevamente de noche, a dormir. Mientras que él salió, entonce(s) Manuel conversaba con las hermana(s) pu(es). $\mathrm{Y}$ ahi le dijeron ellas donde... (d)onde podía alojar:

- Vas a tener que ir a buscar por ahi una parte.

Él le(s) dijo:

-No se preocupen - le(s) dijo-. Total yo me voy a... yo me las arreglo como yo puedo.

Entonce(s) en esa noche, cuando alojó él, alojó... en la misma casa alojó, porque ya tenía esa virtu(d) que el mosquito le había da(d)o. Así que se ganó en una rendija de la casa y ahi alojó pu(es). Entonce(s) al otro día, cuando salió el hombre otra vez, y entonces ahí ya empezó a hacerle(s) pregunta(s) a ellas, a las hermana(s): ¿Por qué le llamaban Cuerpo sin Alma? Él quería saber cuál era el motivo del nombre que tenía, tan raro: le llamaban Cuerpo sin Alma. Entonce(s) a tanto la hermana le dijo:

- Mira - le dijo-, hay... en tal parte hay un... hay un piño de animale(s) que le tiene cuida(d)or - como era rico, tenía un campero ${ }^{50}$ y ése cuidaba los animale(s) _. Y cuando llega él, llegan los animale(s) - le dijo- en esa laguna a tomar agua y sale un toro de adentro. $\mathrm{Y}$ ahí tiene la vida el hombre, en ese animal. Porque dentro del toro - le dijo- hay un... hay un león. Y dentro del león hay una paloma. Y ésa es la vida de él. Y dentro de la paloma hay un huevo. Y ésa es la vida de él.

Entonce(s) él no hallaba cómo hacel.lo. Entonce(s) un día, pensando, dijo:

- ¿Qué voy a hacer?

Entonce(s) luego se le vino un pensamiento, dijo:

- Voy a ir a pedir trabajo a(d)onde este hombre.

Y jue a pedir trabajo, (d)onde el campero que tenía el Cuerpo sin Alma. Claro, ya el otro luego lo recibió, como era rico también ya. Así que lo puso de cuida(d)or de animale(s). Él cuidaba los animale(s). Y eso era lo que él quería pu(es). Así que cuidaba los animale(s) y to(d)os los días los traía al... al lago ese a tomar agua. Y cuando llegaban los animale(s), apenas venían los animales, y salía el toro pu(es), bramando de a(d)entro. Y ahí lo veía él:

- ¿Cómo lo hago?

Pero se portó tan bien el hombre, el Manuelito ahí, que al final el hombre, el patrón que tenía, le regaló un lindo caballo y un buen lazo y una daga grande, así, una cuchilla inmensa, para que se defendiera de los leones, en la montaña.

Y entonce(s) él dijo:

-Ya, con esto estoy bien.

Así que un día dijo:

-Cuando ya salga el toro, con éste lo voy a agarrar.

Así que llevó los animale(s) al agua un día. Jue prepara(d)o. Entonce(s) puso el lazo al pegual ${ }^{51}$ del caballo. Y cuando salió el toro, apenas salió el toro, y lo lació. Le puso lazo y el toro empezó a corcoviar. Él apenas le puso el lazo, se tiró abajo

50 campero: 'persona cuyo oficio es trabajar en el campo' ( $\mathrm{DHCH}$, p. 75).

51 pegual: 'especie de cincha de cuero con una argolla metálica que sirve para amarrar el lazo y sujetar otro animal' (DHCH, p. 164). Marcos A. MoRínigo piensa que esta voz probablemente tenga su origen en alguna variante de la voz hispánica pibuela: Diccionario manual de americanismos (Buenos Aires: Muchnik Editores, 1966), p. 471. 
del caballo. Y el caballo sujetaba al toro. Él jue, vivo el toro, y le rajó la guata ${ }^{52}$ pu(es). Y cuando le rajó la guata al toro, ahi salió el león. Apenas venía asomando el león y agarra el león y le parte la guata igual. Y cuando le partió la guata al león, salió la paloma volando. Y cuando salió la paloma volando, entonce(s) él se convirtió en un... en un peuco ${ }^{53}$. Y lo siguió de atrás. Casi al llegar al cielo, arriba, lo alcanza. Y apenas tomó la paloma, y le abrió la guatita a la paloma. Y le sacó el huevo: un huevito, tenía un huevito.

Entonce(s) cuando ya hizo eso y el cuña(d)o ya estaba enfermo pu(es). Así que cuando... de ahi ya se jue pa(ra) la casa, porque iba sin peligro.

-Porque con éste - dijo- ya lo tengo domina(d)o.

Y cuando llegó allá, entonce(s) salió a atendel.lo una hermana. Le dijo:

-Mi esposo está enfermo.

Entonce(s) él dijo:

-No, yo vengo a vel.lo -le dijo.

Entonce(s) cuando dentró pa(ra) a(d)entro y lo vio el cuña(d)o, le habló, pero ya estaba jodido ${ }^{54}$, estaba bien mal. Y él llevaba el huevito en la mano. Entonce(s) después que conversaron un poco y de ahi le dijo:

- ¿Y éste lo conoces? -le dijo.

Le mostró el huevito. Entonce(s), claro, él lo conoció pu(es). Y como no conociéndolo, le había pedido:

-Deje verlo - le dijo-. Quiero ver el huevito.

Le dijo:

-No.

A tanto exigil.le, entonce(s) le dijo:

- Ya - le dijo-, toma, si querís ${ }^{55}$ vel.lo.

Pescó el huevo y se lo tiró en la frente. Cuando le pegó en la frente, se reventó el huevo y murió el hombre.

Ésa era la vida que tenía. Por eso le llamaban el Cuerpo sin Alma.

$\mathrm{Y}$ entonce(s) ahí luego se adueñó del fundo ahí pu(es). Con las hermana(s) se quedó. Y de ahi después ya tomó caballo ensilla(d)o, trajo varios caballo(s) y una carretela pa(ra) pasar a buscar a sus hermano(s) que estaban en el campo. Así que se vino con una de las hermana(s). Vino a sepultar a sus hermano(s) y después en seguida vino a buscar a sus padre(s) pu(es). Llevó a sus padre(s), sus viejito(s), y para vivir allá con ellos. Al final se hizo rico el Manuelito.

Ahí termina la historia.

\author{
CONSTANTINO CONTRERAS OYARZÚN \\ Dpto. de Lenguas, Literatura y Comunicación \\ Universidad de La Frontera \\ Temuco. Chile
}

\footnotetext{
52 guata: voz de origen mapuche equivalente a 'barriga, vientre, panza' (cfr. DHCH, p. 121).

53 peuco: voz de origen mapuche que designa un 'ave de rapiña, semejante al gavilán' (Parabreteo unicincqus) (DHCH, p. 169).

54 jodido: 'gravemente afectado moral o físicamente' (cfr. $\mathrm{DHCH}$, p. 128).

55 queris: ocasional forma de voseo verbal en esta narración.
} 
Se presenta el análisis de un cuento folklórico registrado recientemente en la Araucanía (sur de Chile). El texto oral, mantenido por un nativo de la etnia mapuche, es una versión del Tipo 302 del índice internacional de Aarne-Thompson y conserva bastante bien los rasgos estructurales del cuento maravilloso de raigambre hispano-europea. A continuación del estudio, se presenta la versión recogida acompanada de notas lingüísticas.

The analysis of a folktale recently recorded in the Araucanian region of southern Chile is presented here. This oral text, recited by a Mapuche native, is a version of Type 302 in the Aarne-Thompson's International Index and manifests very well the structural features of the "Wondrous" in the Hispanic-European Folk Tradition. The original version, accompanied by linguistic notes, is appended to the study. 